\title{
Retention of Ascorbic Acid and Solid Concentration via Centrifugal Freeze Concentration of Orange Juice
}

\author{
P. Orellana-Palma, G. Petzold, I. Andana, N. Torres, and C. Cuevas \\ Group of Emergent Technology and Bioactive Components of Food, Department of Food Engineering, Universidad del Bío-Bío, \\ Casilla 447, Chillán, Chile \\ Correspondence should be addressed to G. Petzold; gpetzold@ubiobio.cl
}

Received 17 May 2017; Accepted 2 August 2017; Published 30 August 2017

Academic Editor: Francisco Barba

Copyright (C) 2017 P. Orellana-Palma et al. This is an open access article distributed under the Creative Commons Attribution License, which permits unrestricted use, distribution, and reproduction in any medium, provided the original work is properly cited.

\begin{abstract}
Freeze concentration of liquid foods produces high-quality concentrates while retaining the heat-labile compounds found in fresh samples. Centrifugal freeze concentration is a cryoconcentration method assisted by an external force, centrifugation, to enhance the separation of concentrate from the ice. When applying centrifugal freeze concentration to orange juice, after the third cryoconcentration cycle, the ascorbic acid content in the concentrate showed retention close to $70 \%$ of the initial value. After the third cycle, the solutes in the concentrate increased 4 times the initial value of the fresh sample with $70 \%$ efficiency. The color evaluation showed that the final concentrated fraction was darker than the fresh juice. The centrifugal freeze concentration in orange juice was effective for obtaining a high-quality concentrate with a higher concentration of solids and ascorbic acid retention.
\end{abstract}

\section{Introduction}

Freeze concentration removes water from liquid foods and solutions through the freezing. In addition, freeze concentration is an effective separation method since the concentrate occupies a smaller weight and space [1] and because consumers only need to add water as the final step of production.

The fruit juice concentration confers commercial benefits in storage, packing, and distribution. In the case of orange juice, the water content is approximately $85-90 \%$; during the concentration step, removing most of the water considerably reduces the bulk. For these reasons, concentrated orange juice production is common worldwide. The primary method of water removal is evaporation, though cryoconcentration and membranes are also used [2].

Fruit juices have become very popular because consumers demand high-quality and nutritious liquid foods [3]. This consumer demand has led to a search for improved food technologies applied to liquid foods (the fruit juice production in particular). Among the methods used for liquid food concentration, freeze concentration is of particular importance due to the subzero temperatures used [4].

Freeze concentration is a concentration technique where an aqueous solution or liquid food is concentrated via partial or total water freezing and separating the ice from the unfrozen liquid fraction [5]. Comparing to other concentration techniques, freeze concentration has some advantages because of the low temperatures used to result in a minimal loss of volatiles [6]. In addition, this technique consumes less energy than traditional concentration techniques by evaporation [7] and protecting the valuable heat-labile components of liquid foods (e.g., ascorbic acid in fruit juices), as noted by Petzold et al. [8].

On the other hand, the more recent freeze concentration studies have focused on single-stage systems (progressive freeze concentration or block freeze concentration) rather than traditional systems by suspension [9-12], since singlestage freeze concentration systems are simpler in construction and equipment operation [10].

In block freeze concentration, a liquid sample is frozen and by means of thawing highly concentrated solutes is obtained, using some assisted techniques to improve the process $[13,14]$. Thus, the ice is a system with channels in which the concentrates rich in solids exit to the outside [15].

Centrifugation is an interesting alternative to assisted technique applied to block freeze concentration. Thus, centrifugation was used by Bonilla-Zavaleta et al. [16] for the 


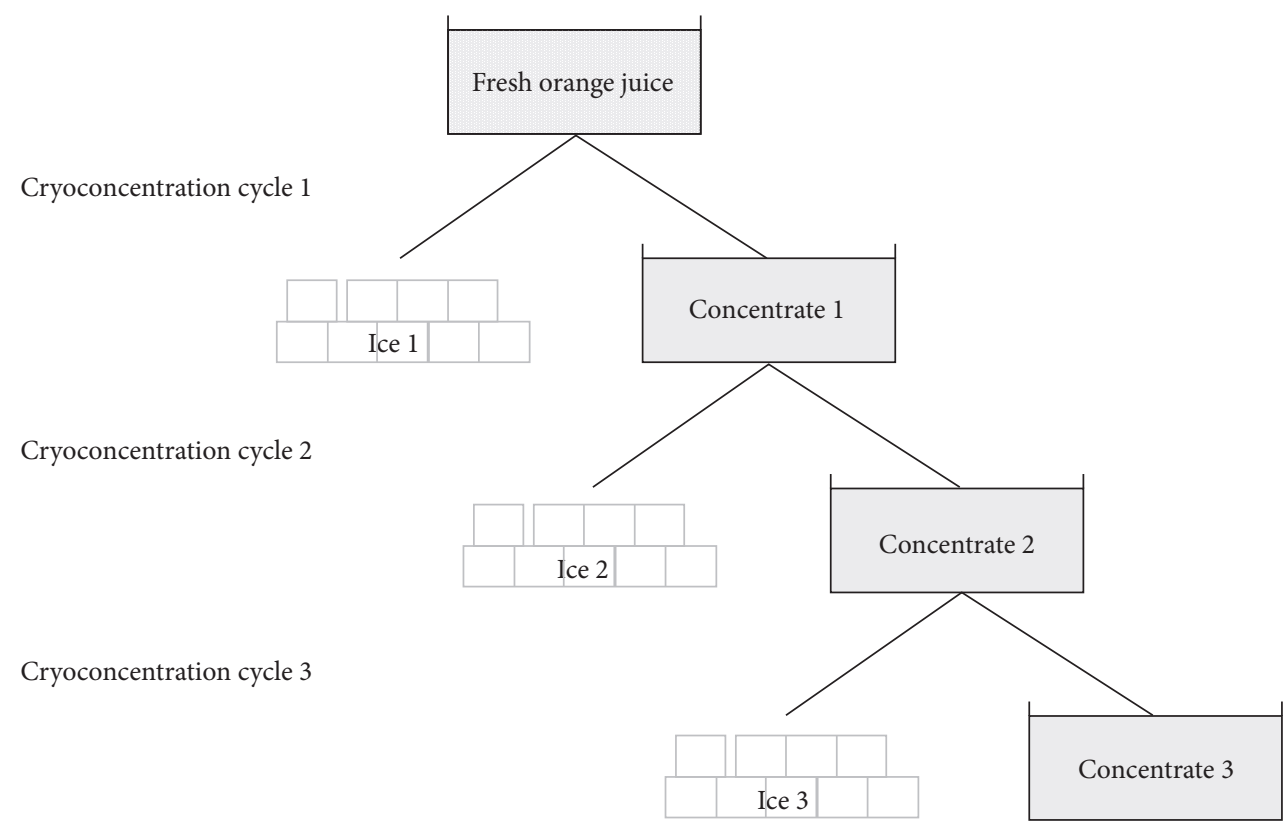

FiguRE 1: General experimental protocol. Fresh orange juice was frozen and then the sample was transferred to a centrifuge to force the separation of concentrate with solutes from the frozen solution in 3 cycles.

concentration of frozen pineapple juice, whereas Luo et al. [17] used this technique to desalinate water. Virgen-Ortíz et al. $[18,19]$ used this assisted technique to cryoconcentrate protein solutions, Petzold and Aguilera [20] presented a centrifugal cryoconcentration method using a sugar solution, and Petzold et al. [21] proposed the application of this assisted technique to blueberry and pineapple juices.

Recently, Orellana-Palma et al. [22] in blueberry, Adorno et al. [23] in strawberries, and Safiei et al. [3] with red grapes proposed the cryoconcentration to protect bioactive compounds, producing concentrated juices with high nutritional value and attractive color. However, there is no scientific literature on the centrifugal freeze concentration as a technology to protect heat-labile components from fruit juices such as ascorbic acid protection from orange juice.

Centrifugation is a very popular separation technique [24]. Freeze concentration assisted by an external force (such as centrifugation) uses the hydraulic structure that exists in the frozen matrix between the ice crystals occluding the solutes. A similar behavior is potentially observed in nature in the frozen structure of the millenary polar ice [25].

The aim of this paper was to study centrifugal freeze concentration in orange juice to protect the ascorbic acid content and concentrate solids.

\section{Materials and Methods}

2.1. Materials. Oranges var. Navel were obtained from a fruit market (Chillán, Chile) and were refrigerated $\left(5^{\circ} \mathrm{C}\right.$, overnight) until processing. Oranges were squeezed, and the juice was filtered to remove out the solids and seeds.

2.2. Experimental Protocol. A general experimental protocol is outlined in Figure 1. Frozen orange juices were transferred to a centrifuge to obtain two fractions: (i) a concentrated solution and (ii) a frozen fraction. The concentrated solution after the first cycle was used as the new solution for the second cycle and so on.

Freezing and centrifugation were carried out by the method of Petzold et al. [21], with minor modifications. Orange juice $(45 \mathrm{ml})$ in centrifugal tubes (internal diameter $D=22 \mathrm{~mm}$ ) was frozen in a static freezer at $-20^{\circ} \mathrm{C}$ for $12 \mathrm{~h}$. The external surfaces of the tubes were covered with foamed polystyrene $(8 \mathrm{~mm}$, thermal conductivity $K=$ $0.035 \mathrm{~W} \mathrm{~m}^{-1} \mathrm{~K}^{-1}$ ) so that the heat transfer during freezing occurred primarily in a unidirectional manner. During freezing, a thermocouple was inserted in the geometric center of the samples to record the temperature of the orange juice samples and calculate the freezing rate $\left(\mathrm{mm} \mathrm{min}^{-1}\right.$ or $\left.\mu \mathrm{m} \mathrm{s}^{-1}\right)$ [1].

The centrifugation step was performed by transferring the frozen samples to a centrifuge (centrifuge Hettich model D7853, Tuttlingen, Germany) at $20^{\circ} \mathrm{C}$ for $25 \mathrm{~min}$ at $4000 \mathrm{rpm}$ (1600 RCF). By centrifuging the frozen samples, the thaw occurs coupled to the application of the external force (centrifugation) that forces the solutes to separate from the ice. Once the sample has been centrifuged, the floating ice is separated from the concentrate using a filter.

The concentrations of fractions $C_{f}$ and $C_{s}$ (solids in the molten frozen fraction and concentrate, resp.) obtained after the assays were analyzed at ambient temperature (approx. $22^{\circ} \mathrm{C}$ ) using an ATAGO refractometer (model PAL-1, Tokyo, Japan) with a precision of $\pm 0.1^{\circ}$ Brix. All measurements were made in triplicate, and each assay was performed six times with two replicates.

2.3. Instrumental and Analytical Determinations. The color was determined as described in detail by Petzold et al. [26], 
using a spectrophotometer (Konica Minolta CM-5, Osaka, Japan), and the results were expressed as CIELAB values.

Ascorbic acid content was determined by titration using 2,6-dichlorophenolindophenol (DCIP), as the Official Methods of Analysis [27]. This method is based on the reduction of DCIP with ascorbic acid in acidic solution. The content of ascorbic acid in fresh and concentrated orange juice was expressed as $\mathrm{mg} / 100 \mathrm{~g}$ solutes.

\subsection{Calculations}

2.4.1. Percentage of Concentrate. The percentage of concentrate was calculated for each cycle using the following equation:

$$
\operatorname{PC}(\%)=\frac{W_{i}^{0}-W_{i}^{f}}{W_{i}^{0}} 100,
$$

where $W_{i}^{0}$ and $W_{i}^{f}$ are the initial and final weight of the frozen fraction, respectively.

2.4.2. Efficiency of Concentration. The efficiency was calculated for each cycle using the following equation:

$$
\eta(\%)=\frac{C_{s}-C_{f}}{C_{s}} 100,
$$

where $C_{s}$ and $C_{f}$ are the concentrations of solids ( ${ }^{\circ}$ Brix) in the concentrated solution and frozen fraction, respectively.

2.4.3. Validation of Experimental Results. To validate the experimental results, a mass balance of each cryoconcentration cycle was made and compared to a predicted value as follows:

$$
W_{p}=\frac{C_{s}-C_{0}}{C_{s}-C_{f}},
$$

where $C_{0}$ is the initial concentration of solids and $W_{p}$ is the predicted value of the ice mass ratio $W$ ( $\mathrm{kg}$ ice $/ \mathrm{kg}$ initial).

The root mean square RMS (4) was calculated to determine the fit between the experimental and predicted values of ice mass ratio ( $W_{e}$ and $W_{p}$, resp.) for $N$ experimental points of each cycle:

$$
\operatorname{RMS}(\%)=100 \sqrt{\frac{\sum\left[\left(W_{e}-W_{p}\right) / W_{e}\right]^{2}}{N}} .
$$

2.5. Statistical Analysis. Data were analyzed using an analysis of variance (ANOVA) and an LSD test using Statgraphics Centurion XVI Software [28] with 95\% confidence levels.

\section{Results and Discussion}

3.1. Solute Content in the Concentrated Solution and Ice. Figure 2 shows the solute content $\left({ }^{\circ} \mathrm{Brix}\right)$ of the concentrated solution $\left(C_{s}\right)$ and ice $\left(C_{f}\right)$ after each freeze concentration cycle. Low solute content characterized the feed orange juice

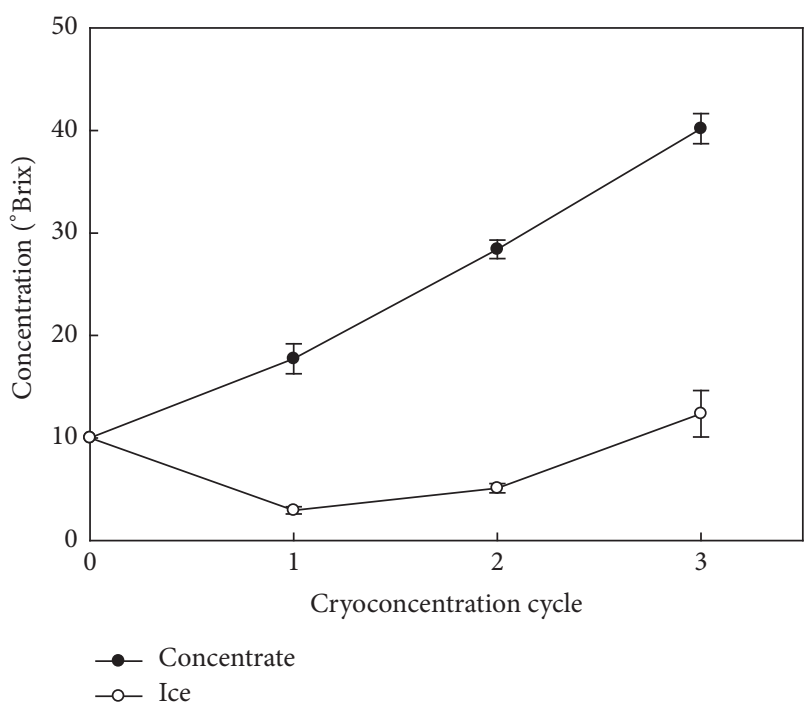

FIGURE 2: Solute content in the concentrated solution and ice fraction as function of the cryoconcentration cycle for orange juice. (0: fresh juice. 1, 2, and 3: fractions obtained at the first, second, and third cryoconcentration cycles, respectively).

with a value of approximately $10^{\circ}$ Brix. By increase the cycles, the solutes in the concentrate increased quasi-linearly, with $R^{2}=0.9984$, and reach approximately 18,29 , and $40^{\circ}$ Brix after the first, second, and third cycles, respectively. In the last cycle, around 4 times the initial concentration of solutes was achieved. This result was higher than that obtained by Sánchez et al. [11] in orange juice cryoconcentrated using a pilot plant unit, where juice concentration increased from 11 to $29^{\circ}$ Brix. Additionally, the result of this work was similar to that achieved by Bonilla-Zavaleta et al. [16], which was approximately $41^{\circ}$ Brix from $12^{\circ}$ Brix pineapple juice by centrifugal freeze concentrate.

On the other hand, the solutes occluded in the ice fraction were estimated to be 3 and $5^{\circ}$ Brix after the first and second freeze concentration cycles, respectively. During the third cycle, the efficiency decreased, and the solids content in the ice augmented to $12^{\circ}$ Brix. These results were better than those obtained previously in our laboratory [21], where the solids concentration increase of 2.5 and 2.7 times was obtained after the third freeze concentration cycle of blueberry and pineapple juices, respectively. This difference can be explained because, in the present study, differently sized tubes were used ( $45 \mathrm{ml}$ versus $12 \mathrm{ml}$ ), which could provoke some stratification or movement of the solids in the freezing step that favors later separation.

This behavior could be attributed to the elution phenomenon, in which solutes movement was produced during ice crystal formation that expelled the solutes to the liquid fraction [9]. This result was also observed by Moreno et al. [29] during the cryoconcentration of coffee extract.

The evolution of the concentrations along the freeze concentration cycles from orange juice was comparable to performance reported when using block cryoconcentration for maple sap [13], whey milk [30], cherry and apricot 


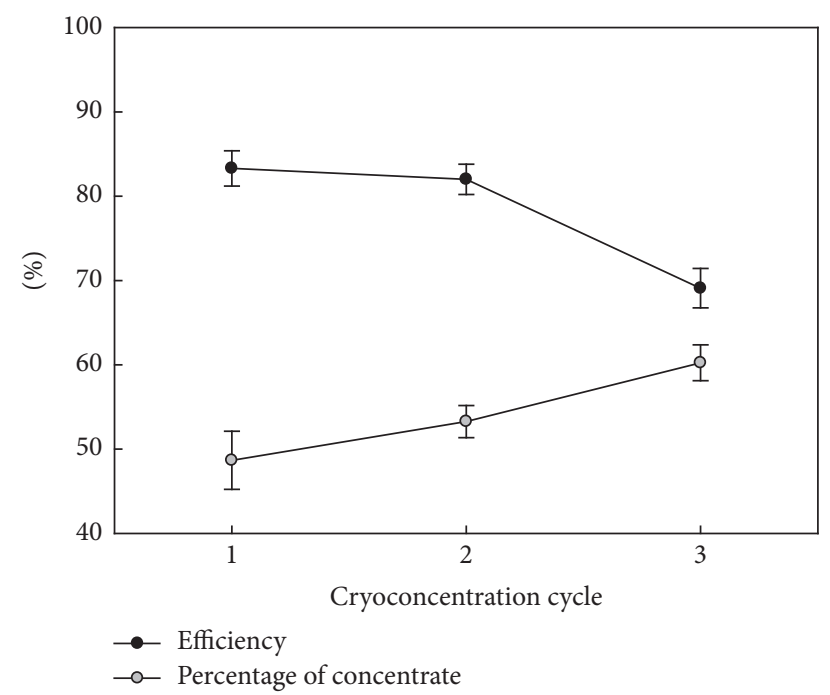

FIGURE 3: Evolution of the efficiency and percentage of concentrate as a function of the cryoconcentration cycle.

juices [14], blueberry and pineapple juices [21], and, recently, strawberry juice [23].

In addition, orange juice has a freezing rate of $0.21 \mathrm{~mm} \mathrm{~min}^{-1}\left(3.5 \mu \mathrm{m} \mathrm{s}^{-1}\right)$, which is lower than the critical value (approximately $8 \mu \mathrm{m} \mathrm{s}^{-1}$ ) reported by Nakagawa et al. [31] and Moreno et al. [29]. These researchers described that, for the freezing rate higher than $8 \mu \mathrm{m} \mathrm{s}^{-1}$, the freezing occurred too rapidly to expect a considerable separation of the concentrate because during the freezing the ice occluded solutes.

3.2. Efficiency and Percentage of Concentrate. The efficiency $(\eta)$ and percentage of concentrate (PC) decreases and increases progressively over the cycles, respectively (see Figure 3). A progressive increase in the percentage of concentrate was observed after the concentration cycles for orange juice and reached $60 \%$, which was close to the values reported in the literature [21,32]. This work of the percentage of concentrate is similar to the value (approximately 50\%) reported by Bonilla-Zavaleta et al. [16] for centrifugal assisted cryoconcentrated pineapple juice and is similar to the general $50 \%$ concentrate obtained by block freeze concentration [15].

These results are explained because the percentage of concentrate is a mathematical direct function of the initial concentration of solutes in the sample to centrifugal freeze concentrate, therefore, as increasing the cryoconcentration cycles (and the solutes concentration increases), it is expected that the percentage of concentrate will increase [20]. In addition, this effect could be associated with a freezing point depression as demonstrated in a previous work [21].

For efficiency, a progressive decrease was observed for the orange juice over the cycles in a similar fashion to previous research [21] and an opposite slope in percentage of concentrate is observed, analogous behavior to the previous report [20,21]. An increase in the initial concentration at each cryoconcentration cycle explained this effect and implied that

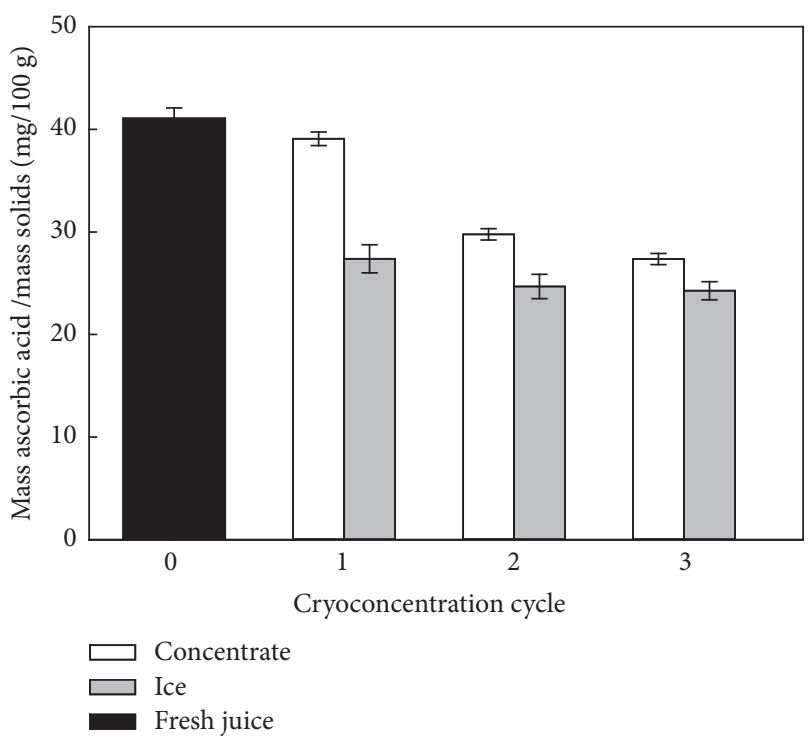

FIGURE 4: Evolution of the ascorbic acid content ( $\mathrm{mg} / 100 \mathrm{~g}$ solids) in the concentrated and ice fraction as a function of the cryoconcentration cycle.

the higher solid in concentrate is, the higher viscosity is obtained, and the freeze concentration efficiency depended generally on the viscosity of the concentrate $[23,33]$. The obtained efficiency values (80-70\%) were similar to the values obtained by Luo et al. [17], with an efficiency of approximately $73 \%$ (from $4300 \mathrm{ppm}$ of solutes) and recently, Adorno et al. [23] obtained 74\% efficiency of strawberries concentrated by this technology.

3.3. Ascorbic Acid Content. Figure 4 shows the ascorbic acid content (in $\mathrm{mg} / 100 \mathrm{~g}$ solids) after each cryoconcentration cycle for orange juice. The feed orange juice had an ascorbic acid content of approximately $41 \mathrm{mg} / 100 \mathrm{~g}$ solids $(50 \mathrm{mg} / 100 \mathrm{ml})$, a value close to that reported by Sandhu and Minhas [2]. By increasing the cycles, the ascorbic acid content decreases progressively, although as expected with a greater presence in the concentrated phase. This decrease in the ascorbic acid content is explained because the method of centrifugal freeze concentration supposes the withdrawal in each cycle of the resulting ice, losing the solutes present and therefore of the ascorbic acid (see Figure 1). In these conditions, at the end of the process (third cycle), the concentrate reaches a value close to $28 \mathrm{mg} / 100 \mathrm{~g}$ solids, representing a retention close to $70 \%$ of the initial value.

This retention effect of the cryoconcentration in the content of ascorbic acid was reported by Aider and de Halleux [14] who used apricot and cherry juices, respectively. In addition, Liu et al. [34], using progressive freeze concentration, described that freeze concentrated tomato juice showed no differences in ascorbic acid content compared with fresh tomato juice.

From a practical point of view, these results confirm that centrifugal freeze concentration is an effective technique for protecting the important heat-labile components of liquid foods, such as ascorbic acid in orange juice. 
TABLE 1: Color evaluation in fresh and concentrate orange juice ${ }^{\ddagger}$.

\begin{tabular}{|c|c|c|c|c|c|c|c|}
\hline Cycle $^{\neq \neq}$ & $L^{*}$ & $a$ & $b$ & $h_{a b}^{*}$ & $C_{a b}^{*}$ & $\left(\Delta E^{*}\right)$ & $\left(\Delta E^{*}\right)^{f \neq \neq}$ \\
\hline 0 & $39.49 \pm 1.72^{c}$ & $19.47 \pm 0.05^{\mathrm{b}}$ & $48.49 \pm 0.25^{\mathrm{a}}$ & $68.03 \pm 0.14^{\mathrm{b}}$ & $52.25 \pm 0.21^{\mathrm{a}}$ & - & - \\
\hline 1 & $37.76 \pm 2.28^{c}$ & $17.64 \pm 0.61^{\mathrm{a}}$ & $54.51 \pm 2.50^{\mathrm{b}}$ & $71.92 \pm 1.28^{\mathrm{b}}$ & $57.31 \pm 2.25^{\mathrm{b}}$ & $7.47 \pm 3.09^{\mathrm{a}}$ & $11.56 \pm 2.39^{\mathrm{a}}$ \\
\hline 2 & $32.25 \pm 1.69^{\mathrm{b}}$ & $17.56 \pm 0.47^{\mathrm{a}}$ & $62.88 \pm 3.06^{c}$ & $65.29 \pm 2.95^{\mathrm{a}}$ & $74.25 \pm 1.14^{\mathrm{c}}$ & $17.35 \pm 3.99^{\mathrm{b}}$ & $26.04 \pm 3.14^{b}$ \\
\hline 3 & $28.25 \pm 0.17^{\mathrm{a}}$ & $19.05 \pm 0.54^{\mathrm{b}}$ & $66.08 \pm 2.58^{c}$ & $68.77 \pm 2.63^{b}$ & $73.80 \pm 0.61^{\mathrm{c}}$ & $20.89 \pm 3.23^{\mathrm{b}}$ & $34.32 \pm 3.11^{\mathrm{c}}$ \\
\hline
\end{tabular}

${ }^{\ddagger}$ Significant differences at $5.0 \%$ between homogeneous groups in each variable according to a least significant difference (LSD) test are identified by different

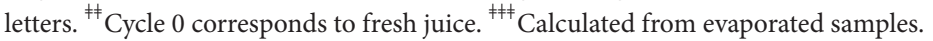

3.4. Color Evaluation. Table 1 illustrates the CIELAB values of fresh orange juice and concentrate samples after each cryoconcentration cycle. As expected, a clear reduction in the CIELAB parameters was observed. Cryoconcentrate samples showed lower $L^{*}$ values than fresh juice, which indicated that cryoconcentrates were darker than the fresh orange juice. These differences in CIELAB values were similar to the differences published previously for pomegranate cryoconcentrate compared with the fresh sample [35].

In addition, the total color difference $\left(\Delta E^{*}\right)$ of the freeze concentrate samples showed $\Delta E^{*}$ between fresh orange juice and concentrate were, in all cases, higher than the human visual discrimination threshold $\left(\Delta E^{*}>3\right)$ [36], reaching $\Delta E^{*}$ values of $>20$ CIELAB units after the third cryoconcentration cycle. Finally, $\Delta E^{*}$ of evaporated samples showed in general higher values than the cryoconcentrated samples, reaching in this case $\Delta E^{*}$ values of $>30$ CIELAB units, confirming the convenience of the use of cryoconcentration over evaporation in the preservation of the original characteristics of the fresh sample [8].

3.5. Validation of Experimental Results. To validate the results, a balance of ice mass ratio (experimental and predicted) of each cryoconcentration cycle was performed (3).

The ice mass ratio $(W)$ had an expected downward tendency along with the cryoconcentration cycles (Figure 5). This performance was attributed to the increased percentage of concentrate along the cycles (Figure 3 ) and was in agreement with observations between the experimental $\left(W_{e}\right)$ and predicted $\left(W_{p}\right)$ ice mass ratios (Figure 5$)$. The RMS values over the cycles fluctuated between $2.0 \%$ and $5.1 \%$. These RSM values were lower than $25 \%$, which Lewicki [37] considered being an acceptable fit, and these values were close to those reported in the literature $[11,21,32,38,39]$.

During centrifugal freeze concentration application of orange juice, the ice acts as a carcass through which the solutes pass through channels among ice crystals in a similar manner as reported for freeze concentration assisted by vacuum [15] and centrifugal freeze concentration of sucrose solutions and fruit juices [21,32].

\section{Conclusion}

Centrifugal freeze concentration is an effective technology to concentrate the solids from orange juice. Using this technique the concentration of solids, after the third cryoconcentration cycle, increased 4 times compared to the initial concentration and the ascorbic acid content in the concentrate showed

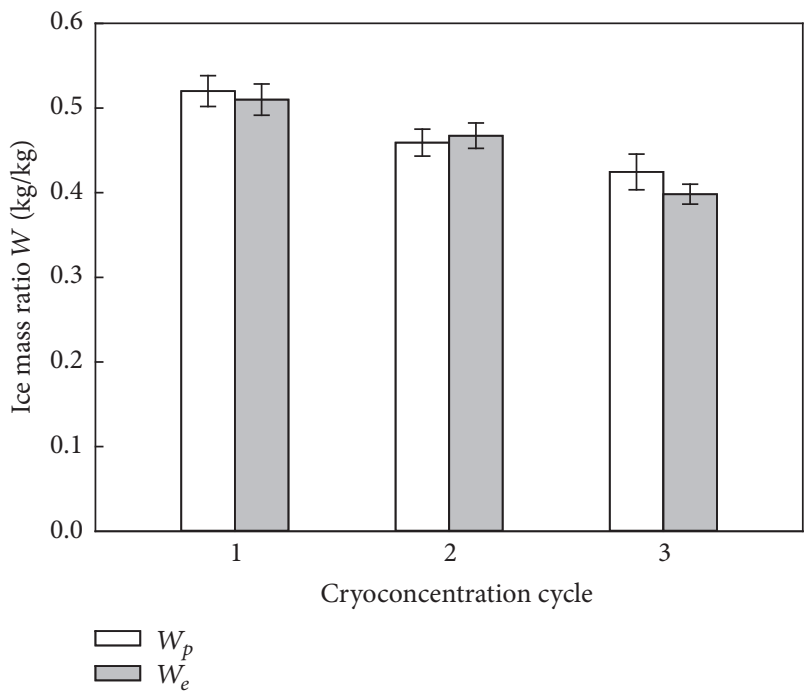

FIGURE 5: Experimental $\left(W_{e}\right)$ and predicted $\left(W_{p}\right)$ ice mass ratios as a function of cryoconcentration cycle.

retention close to $70 \%$ of the initial value. The performance of centrifugal freeze concentration of orange juice was attributed to the solutes which pass through channels among ice crystals.

\section{Conflicts of Interest}

The authors declare that there are no conflicts of interest regarding the publication of this paper.

\section{Acknowledgments}

Author Guillermo Petzold is grateful for the financial support provided by CONICYT through FONDECYT Project no. 11140747 and Fondo de Apoyo a la Participación a Eventos Internacionales (Universidad del Bío-Bío). Author Patricio Orellana-Palma is grateful for the financial support provided by CONICYT-Chile through the Human Capital Formation Advanced Program National Doctoral Fellowship 2016 (Folio 21160514).

\section{References}

[1] H. Ramaswamy and M. Marcotte, Food Processing: Principles and Applications, Taylor \& Francis, Boca Raton, Fla, USA, 2006. 
[2] K. S. Sandhu and K. S. Minhas, "Oranges and citrus juices," in Handbook of Fruits and Fruit Processing, Y. H. Hui, Ed., Blackwell Publishing, Ames, Iowa, USA, 2006.

[3] N. Z. Safiei, N. Ngadi, A. Johari, Z. Y. Zakaria, and M. Jusoh, "Grape Juice Concentration by Progressive Freeze Concentrator Sequence System," Journal of Food Processing and Preservation, vol. 41, no. 1, Article ID e12910, 2017.

[4] M. Raventós, E. Hernández, and J. Auleda, "Freeze Concentration Applications in Fruit Processing," in Advances in Fruit Processing Technologies, S. Rodriguez and F. A. N. Fernandes, Eds., vol. 20123161 of Contemporary Food Engineering, pp. 263286, CRC Press, Boca Raton, Fla, USA, 2012.

[5] M. Aider and W. B. Ounis, "Skim milk cryoconcentration as affected by the thawing mode: Gravitational vs. microwaveassisted," International Journal of Food Science and Technology, vol. 47, no. 1, pp. 195-202, 2012.

[6] K. R. Morison and R. W. Hartel, "Evaporation and freeze concentration," in Handbook of Food Engineering, D. R. Heldman and D. B. Lund, Eds., CRC Press, New York, NY, USA, 2007.

[7] N. Pazmiño, M. Raventos, E. Hernández et al., "Continuous System of Freeze Concentration of Sucrose Solutions: Process Parameters and Energy Consumption," Journal of Food Technology and Preservation, vol. 1, pp. 1-5, 2016.

[8] G. Petzold, P. Orellana, J. Moreno, J. Junod, and G. Bugueño, "Freeze concentration as a technique to protect valuable heatlabile components of foods," in Innovative Processing Technologies for Foods with Bioactive Compounds, J. J. Moreno, Ed., Contemporary Food Engineering, pp. 183-194, CRC Press, Boca Raton, Fla, USA, 2016.

[9] G. Petzold and J. M. Aguilera, "Ice morphology: Fundamentals and technological applications in foods," Food Biophysics, vol. 4, no. 4, pp. 378-396, 2009.

[10] J. Sánchez, Y. Ruiz, J. M. Auleda, E. Hernández, and M. Raventós, "Review. Freeze concentration in the fruit juices industry," Food Science and Technology International, vol. 15, no. 4, pp. 303-315, 2009.

[11] J. Sánchez, Y. Ruiz, M. Raventós, J. M. Auleda, and E. Hernández, "Progressive freeze concentration of orange juice in a pilot plant falling film," Innovative Food Science and Emerging Technologies, vol. 11, no. 4, pp. 644-651, 2010.

[12] O. Miyawaki, S. Kato, and K. Watabe, "Yield improvement in progressive freeze-concentration by partial melting of ice," Journal of Food Engineering, vol. 108, no. 3, pp. 377-382, 2012.

[13] M. Aider and D. de Halleux, "Passive and microwave-assisted thawing in maple sap cryoconcentration technology," Journal of Food Engineering, vol. 85, no. 1, pp. 65-72, 2008.

[14] M. Aider and D. de Halleux, "Production of concentrated cherry and apricot juices by cryoconcentration technology," LWT - Food Science and Technology, vol. 41, no. 10, pp. 17681775, 2008.

[15] M. Aider and D. de Halleux, "Cryoconcentration technology in the bio-food industry: Principles and applications," LWT - Food Science and Technology, vol. 42, no. 3, pp. 679-685, 2009.

[16] E. Bonilla-Zavaleta, E. J. Vernon-Carter, and C. I. Beristain, "Thermophysical properties of freeze-concentrated pineapple juice," Italian Journal of Food Science, vol. 18, no. 4, pp. 367-376, 2006.

[17] C.-S. Luo, W.-W. Chen, and W.-F. Han, "Experimental study on factors affecting the quality of ice crystal during the freezing concentration for the brackish water," Desalination, vol. 260, no. 1-3, pp. 231-238, 2010.
[18] J. J. Virgen-Ortíz, V. Ibarra-Junquera, J. A. Osuna-Castro, P. Escalante-Minakata, N. A. Mancilla-Margalli, and J. D. J. Ornelas-Paz, "Method to concentrate protein solutions based on dialysis-freezing- centrifugation: Enzyme applications," Analytical Biochemistry, vol. 426, no. 1, pp. 4-12, 2012.

[19] J. J. Virgen-Ortíz, V. Ibarra-Junquera, P. Escalante-Minakata et al., "Improving sodium dodecyl sulfate polyacrylamide gel electrophoresis detection of low-abundance protein samples by rapid freeze centrifugation," Analytical Biochemistry, vol. 443, no. 2, pp. 249-251, 2013.

[20] G. Petzold and J. M. Aguilera, "Centrifugal freeze concentration," Innovative Food Science and Emerging Technologies, vol. 20, pp. 253-258, 2013.

[21] G. Petzold, J. Moreno, P. Lastra, K. Rojas, and P. Orellana, "Block freeze concentration assisted by centrifugation applied to blueberry and pineapple juices," Innovative Food Science and Emerging Technologies, vol. 30, pp. 192-197, 2015.

[22] P. Orellana-Palma, G. Petzold, L. Pierre, and J. M. Pensaben, "Protection of polyphenols in blueberry juice by vacuumassisted block freeze concentration," Food and Chemical Toxicology, In press.

[23] W. T. Adorno, K. Rezzadori, G. D. Arend et al., "Enhancement of phenolic compounds content and antioxidant activity of strawberry (Fragaria $\times$ ananassa) juice by block freeze concentration technology," International Journal of Food Science and Technology, vol. 52, no. 3, pp. 781-787, 2017.

[24] R. T. Toledo, Fundamentals of Food Process Engineering, Springer, New York, NY, USA, 3rd edition, 2007.

[25] A. W. Rempel, E. D. Waddington, J. S. Wettlaufer, and M. G. Worster, "Possible displacement of the climate signal in ancient ice by premelting and anomalous diffusion," Nature, vol. 411, no. 6837, pp. 568-571, 2001.

[26] G. Petzold, P. Orellana, J. Moreno, E. Cerda, and P. Parra, "Vacuum-assisted block freeze concentration applied to wine," Innovative Food Science and Emerging Technologies, vol. 36, pp. 330-335, 2016.

[27] AOAC, Official Methods of Analysis of AOAC International, Association of Official Analysis Chemists International, Gaithersburg, Md, USA, 18th edition, 2010.

[28] Statgraphics, Statgraphics Centurion XVI, StatPoint Technologies Inc., Warrenton, Va, USA, 2009.

[29] F. L. Moreno, M. Raventós, E. Hernández, and Y. Ruiz, "Block freeze-concentration of coffee extract: Effect of freezing and thawing stages on solute recovery and bioactive compounds," Journal of Food Engineering, vol. 120, no. 1, pp. 158-166, 2014.

[30] M. Aider, D. de Halleux, and I. Melnikova, "Skim acidic milk whey cryoconcentration and assessment of its functional properties: Impact of processing conditions," Innovative Food Science and Emerging Technologies, vol. 10, no. 3, pp. 334-341, 2009.

[31] K. Nakagawa, S. Maebashi, and K. Maeda, "Freeze-thawing as a path to concentrate aqueous solution," Separation and Purification Technology, vol. 73, no. 3, pp. 403-408, 2010.

[32] G. Petzold, K. Niranjan, and J. M. Aguilera, "Vacuum-assisted freeze concentration of sucrose solutions," Journal of Food Engineering, vol. 115, no. 3, pp. 357-361, 2013.

[33] J. Welti-Chanes, D. Bermúdez, A. Valdez-Fragoso, H. MújicaPaz, and S. M. Alzamora, "Principles of freeze-concentration and freeze-drying," in Handbook of Frozen Foods, Y. H. Hui, P. Cornillon, I. G. Legaretta, M. H. Lim, K. D. Murrell, and W. Nip, Eds., Marcel Dekker, New York, NY, USA, 2004. 
[34] L. Liu, O. Miyawaki, and K. Hayakawa, "Progressive FreezeConcentration of Tomato Juice," Food Science and Technology Research, vol. 5, no. 1, pp. 108-112, 1999.

[35] F. Khajehei, M. Niakousari, M. H. Eskandari, and M. Sarshar, "Production of Pomegranate Juice Concentrate by Complete Block Cryoconcentration Process," Journal of Food Process Engineering, vol. 38, no. 5, pp. 488-498, 2015.

[36] M. Melgosa, E. Hita, A. J. Poza, D. H. Alman, and R. S. Berns, "Suprathreshold color-difference ellipsoids for surface colors," Color Research and Application, vol. 22, no. 3, pp. 148-155, 1997.

[37] P. P. Lewicki, "Raoult's law based food water sorption isotherm," Journal of Food Engineering, vol. 43, no. 1, pp. 31-40, 2000.

[38] E. Hernández, M. Raventós, J. M. Auleda, and A. Ibarz, "Freeze concentration of must in a pilot plant falling film cryoconcentrator," Innovative Food Science and Emerging Technologies, vol. 11, no. 1, pp. 130-136, 2010.

[39] P. Orellana-Palma, G. Petzold, N. Torres, and M. Aguilera, "Elaboration of orange juice concentrate by vacuum-assisted block freeze concentration," Journal of Food Processing and Preservation, In press. 

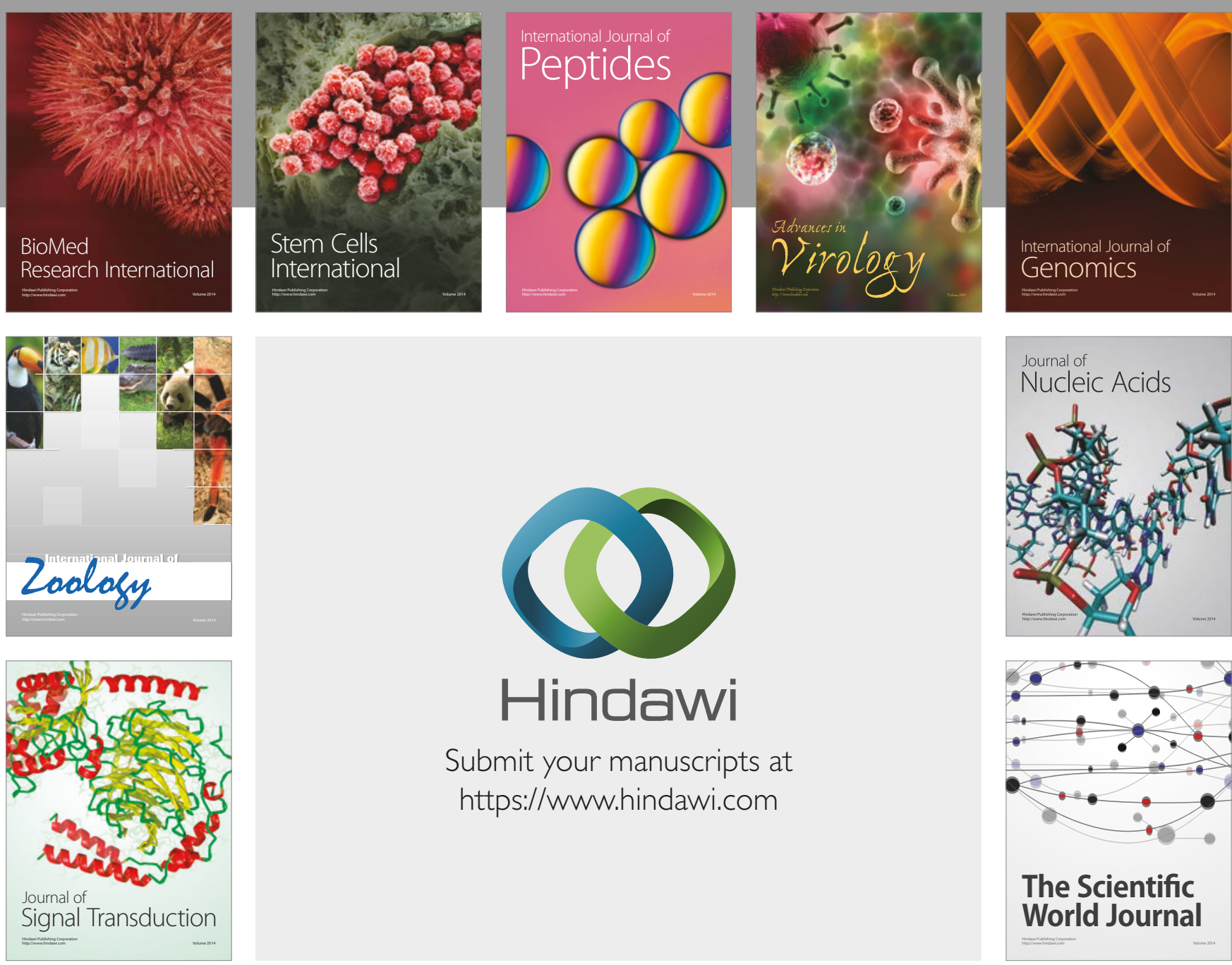

Submit your manuscripts at

https://www.hindawi.com
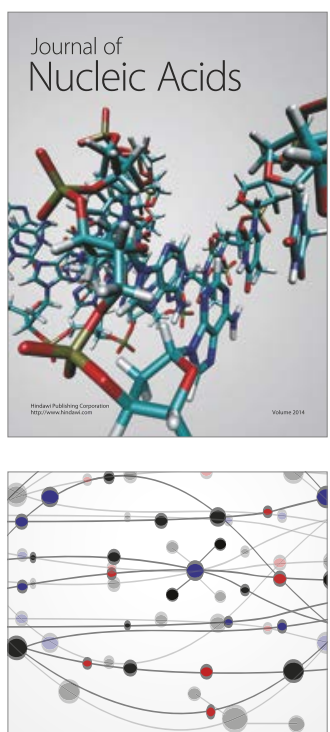

The Scientific World Journal

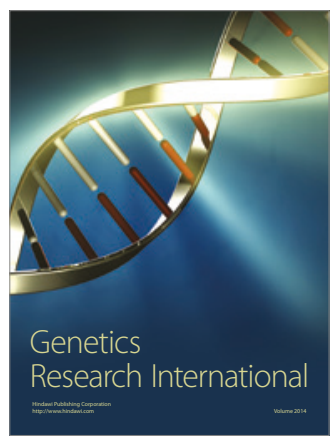

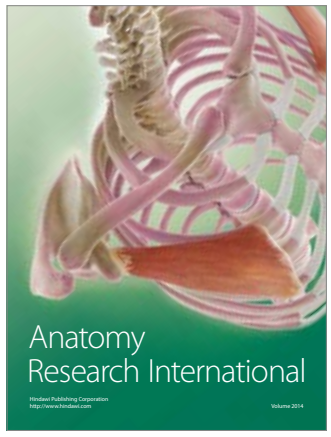

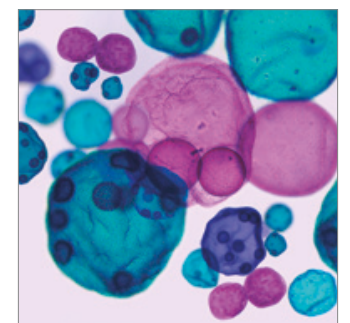

International Journal of Microbiology
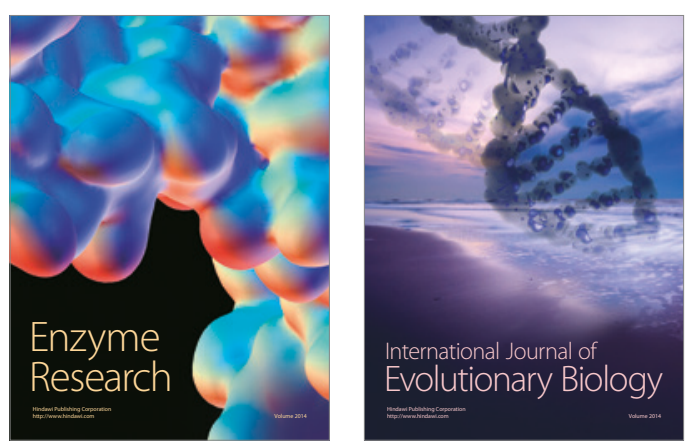
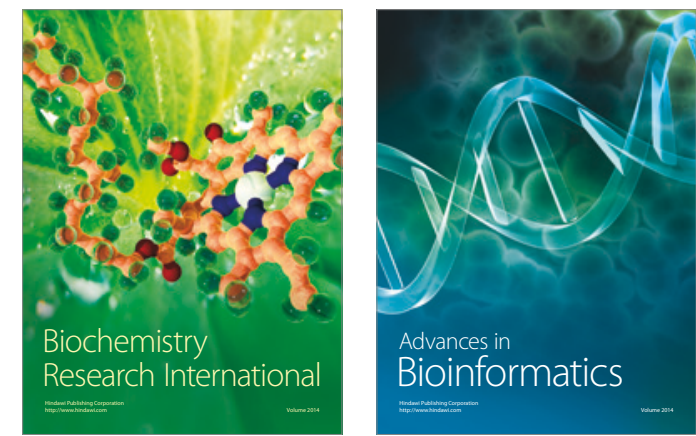

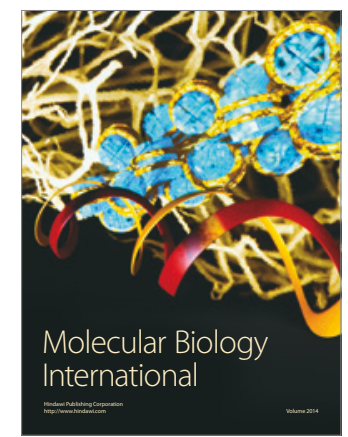

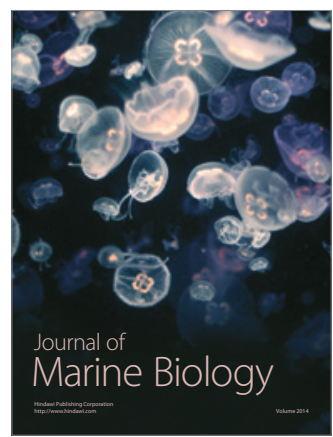

